\title{
Mechanisms of Deafferentation-Induced Plasticity in Human Motor Cortex
}

\author{
Ulf Ziemann, Mark Hallett, and Leonardo G. Cohen \\ Human Cortical Physiology Section, National Institute of Neurological Disorders and Stroke, National Institutes of Health, \\ Bethesda, Maryland 20892-1428
}

\begin{abstract}
Deafferentation induces rapid plastic changes in the cerebral cortex, probably via unmasking of pre-existent connections. Several mechanisms may contribute, such as changes in neuronal membrane excitability, removal of local inhibition, or various forms of short- or long-term synaptic plasticity. To understand further the mechanisms involved in cortical plasticity, we tested the effects of CNS-active drugs in a plasticity model, in which forearm ischemic nerve block (INB) was combined with low-frequency repetitive transcranial magnetic stimulation (rTMS) of the deafferented human motor cortex. rTMS was used to upregulate the plastic changes caused by INB. We studied six healthy subjects. In two control sessions without drug application, INB plus rTMS increased the motor-evoked potential (MEP) size and decreased intracortical inhibition (ICl) measured with single- and paired-pulse TMS in the biceps brachii muscle proximal to INB. A single oral dose of the benzodiazepine lorazepam $\left(2 \mathrm{mg}\right.$ ) or the voltage-gated $\mathrm{Na}^{+}$and $\mathrm{Ca}^{2+}$ channel
\end{abstract}

The adult mammalian sensorimotor cortex can reorganize rapidly, within minutes to hours, in response to peripheral lesions (Merzenich et al., 1983; Calford and Tweedale, 1988, 1991a,b; Sanes et al., 1988; Donoghue et al., 1990; Byrne and Calford, 1991; Kolarik et al., 1994; Silva et al., 1996; Borsook et al., 1998) or as a consequence of motor learning (Grafton et al., 1992; Recanzone et al., 1992; Pascual-Leone et al., 1994, 1995; Karni et al., 1995; Donoghue et al., 1996; Nudo et al., 1996). There is good evidence that these rapid reorganizational processes are mediated by the unmasking of existent but latent corticocortical connections (Schieber and Hibbard, 1993; Donoghue et al., 1996; Huntley, 1997; Sanes and Donoghue, 1997) and that the mechanisms involved include removal of local inhibition (Jacobs and Donoghue, 1991) and changes in synaptic efficacy. One example for short-term synaptic enhancement is post-tetanic potentiation (PTP), which depends on an increase in calcium concentration in presynaptic terminals and decays in the order of minutes (Fisher et al., 1997). An example for a sustained strengthening of synapses is long-term potentiation (LTP), which was first described in the hippocampus (Bliss and Lømo, 1973) but is also present in the mammalian neocortex where it is mediated via NMDA re-

Received April 6, 1998; revised June 10, 1998; accepted June 15, 1998.

This work was supported by Grant $\mathrm{Zi} \mathrm{542/1-1} \mathrm{to} \mathrm{U.Z.} \mathrm{from} \mathrm{the} \mathrm{Deutsche}$ Forschungsgemeinschaft. We thank Dr. M. A. Rogawski for excellent discussion, B. Corwell for help in some of the experiments, and B. J. Hessie for skillful editing of this manuscript.

Correspondence should be addressed to Dr. Ulf Ziemann or Dr. Leonardo G. Cohen, Building 10, Room 5N234, National Institutes of Health, 10 Center Drive, MSC-1428, Bethesda, MD 20892-1428.

Copyright (C) 1998 Society for Neuroscience $0270-6474 / 98 / 187000-08 \$ 05.00 / 0$ blocker lamotrigine (300 mg) abolished these changes. The NMDA receptor blocker dextromethorphan (150 mg) suppressed the reduction in $\mathrm{ICI}$ but not the increase in MEP size. With sleep deprivation, used to eliminate sedation as a major factor of these drug effects, INB plus rTMS induced changes similar to that seen in the control sessions. The findings suggest that (1) the INB plus rTMS-induced increase in MEP size involves rapid removal of GABA-related cortical inhibition and short-term changes in synaptic efficacy dependent on $\mathrm{Na}^{+}$or $\mathrm{Ca}^{2+}$ channels and that (2) the long-lasting (>60 min) reduction in $\mathrm{ICl}$ is related to long-term potentiation-like mechanisms given its duration and the involvement of NMDA receptor activation.

Key words: mechanisms of cortical plasticity; transient ischemic forearm deafferentation; pharmacological blockade of plasticity; GABA; glutamate; paired-pulse inhibition; human motor cortex ceptors and usually requires the downregulation of local inhibitory circuits (Artola and Singer, 1987; Iriki et al., 1989; Artola et al., 1990; Kirkwood et al., 1993; Hess and Donoghue, 1994; Kirkwood and Bear, 1994; Castro-Alamancos et al., 1995; Hess et al., 1996).

The present experiments used temporary ischemic limb deafferentation, an established experimental model of cortical plasticity in humans (Brasil-Neto et al., 1992, 1993; Ridding and Rothwell, 1995, 1997; Ziemann et al., 1998), combined with low-frequency repetitive transcranial magnetic stimulation (rTMS) of the motor cortex contralateral to ischemia. When tested with single- and paired-pulse TMS, deafferentation leads to a rapid increase in the amplitudes of motor-evoked potentials (MEPs) in muscles proximal to the ischemic nerve block without changes in motor threshold (MT). rTMS upregulates the ischemia-induced MEP increase and, in addition, induces a longlasting (>60 min) decrease in intracortical inhibition (ICI) (Ziemann et al., 1998). These measures reflect different aspects of motor cortical excitability. MEP size explores in this paradigm excitatory synaptic transmission in the motor cortex (Brasil-Neto et al., 1993), MT probes neuronal membrane excitability (Mavroudakis et al., 1994; Ziemann et al., 1996b; Chen et al., 1997b), and ICI measures strong GABA-dependent inhibitory and weaker NMDA-dependent excitatory interneuronal circuits in the motor cortex (Ziemann et al., 1996a,b; Liepert et al., 1997).

Identification of the mechanisms of plasticity in adult human cortex is an important step toward the development of rationally founded treatment strategies in neurorehabilitation. To understand the mechanisms underlying ischemic nerve block (INB) 
plus rTMS-induced plasticity better, we tested whether CNSactive drugs, in particular a blocker of NMDA receptors (dextromethorphan), a $\mathrm{GABA}_{\mathrm{A}}$ receptor agonist (lorazepam), and a blocker of voltage-gated $\mathrm{Na}^{+}$and $\mathrm{Ca}^{2+}$ channels (lamotrigine), suppress this form of plasticity. Suppressive effects by drugs acting via specific mechanisms of action would allow us to identify the involvement of these mechanisms in the plastic process.

\section{MATERIALS AND METHODS}

Subjects. We studied six healthy right-handed men (mean age, $25.5 \pm 4.3$ years). Each subject was tested in six separate sessions. Another three subjects were screened but excluded, because the target muscle [biceps brachii (BB)] was not sufficiently excitable by focal TMS. All subjects gave their written informed consent for the study, and the protocol was approved by the Institutional Review Board.

Measurements of motor excitability. Subjects were seated comfortably in a reclining chair. A surface EMG was recorded from the BB and the abductor pollicis brevis (APB) of the nondominant left arm with silversilver chloride cup electrodes in a belly-tendon montage. After amplification and bandpass $(0.1-2.5 \mathrm{kHz})$ filtering (Counterpoint electromyograph; Dantec Electronics, Skovlunde, Denmark), the EMG signal was digitized (analog-to-digital rate of $5 \mathrm{kHz}$ ) and fed into an IBM 486 AT-compatible laboratory computer for off-line analysis.

Focal TMS was applied to the motor cortex on the right side. A figure eight-shaped coil was connected to two Magstim 200 magnetic stimulators through a BiStim module (Magstim, Whitland, Dyfed, UK). The coil was placed tangentially to the scalp with the handle pointing backward and rotated away from the midline by $\sim 45^{\circ}$. The current induced in the brain was therefore directed approximately perpendicular to the line of the central sulcus, a condition optimal for activating the corticospinal system trans-synaptically (Kaneko et al., 1996). The coil was moved over the area of the motor cortex on the right side to determine the optimal positions for eliciting MEPs of maximal amplitude in the BB and APB. These positions were marked on the scalp with a pen to ensure an identical coil placement throughout the experiment. The resting MT was determined for both muscles at their optimal stimulation sites to the nearest $1 \%$ of the maximum output of the stimulator and was the minimum stimulus intensity that produced MEPs $\geq 50 \mu \mathrm{V}$ in at least 5 of 10 consecutive trials. MEP size in the BB was obtained in 10 trials each at stimulus intensities of 130 and $150 \%$ of the MT of the BB. MEP amplitudes were measured peak-to-peak in the single trials, and averages were then calculated for the two stimulus intensities.

A paired conditioning-test stimulus technique (Kujirai et al., 1993; Ziemann et al., 1996c) was used to study ICI in the BB. The test stimulus was of a suprathreshold intensity to produce a control MEP of 200-500 $\mu \mathrm{V}$ in peak-to-peak amplitude when given alone. The conditioning stimulus was set to $80 \%$ of the MT of the APB. This low-intensity stimulus does not produce changes in the excitability of motoneurons at the spinal cord level (Kujirai et al., 1993), so that any changes in the size of the control MEP are probably attributable to intracortical mechanisms, as was recently proved in studies of spinal cord-evoked potentials (Nakamura et al., 1997; Di Lazzaro et al., 1998). Because the MT is usually slightly higher for the BB than for the APB (Brouwer and Ashby, 1990) (also see Table 2), reference to the MT of the APB for setting the conditioning stimulus intensity safely avoids any spinal contribution when measuring the ICI for the BB. Interstimulus intervals (ISIs) of 2 and $4 \mathrm{msec}$ were tested because previous work has shown a clear and consistent inhibitory effect of the conditioning stimulus at these intervals in healthy subjects (Kujirai et al., 1993; Ziemann et al., 1996b). The three conditions (test stimulus alone and paired stimulation at ISIs of 2 and 4 msec) were intermixed in a pseudorandomized order based on single trials and were applied eight times each. The peak-to-peak MEP amplitudes were measured in the single trials, and averages were calculated. ICI was then expressed as the ratio of the average MEP induced by paired stimulation to the control mean (Kujirai et al., 1993). All measurements were taken with the target muscles at rest. Voluntary relaxation was monitored by continuous audiovisual feedback of the EMG signal. The intertrial interval was $5 \mathrm{sec}$ for all measurements.

Experimental protocol and interventions. Each of the six sessions followed the same protocol. First, the preischemic measurements of motor excitability (MT, MEP size, and ICI) were obtained. Then a pneumatic tourniquet was placed just below the elbow. The tourniquet was inflated to $220-250 \mathrm{mmHg}$. Low-frequency rTMS was applied to the optimal scalp position for activating the $\mathrm{BB}$ with a water-cooled figure eightshaped coil and a Cadwell rapid-rate magnetic stimulator (Cadwell Laboratories, Kennewick, WA). The stimulus rate was $0.1 \mathrm{~Hz}$, and the stimulus intensity was $120 \%$ of the MT for the BB. rTMS started when the tourniquet was inflated and continued until MEPs in the APB were abolished (on average, after $\sim 30 \mathrm{~min}$; see Table 1), indicating complete motor block to the hand. Five minutes later, motor excitability was remeasured ("late into ischemia" measurements). Immediately thereafter, the tourniquet was deflated. Another two sets of excitability measurements were taken 20 and $60 \mathrm{~min}$ after the tourniquet was released. Low-frequency rTMS at $0.1 \mathrm{~Hz}$ does not induce plastic changes in the absence of INB (Chen et al., 1997a; Ziemann et al., 1998). In this study, we used rTMS in combination with INB to enhance the increase in MEP size seen with INB alone and, in addition, to induce a long-lasting decrease in ICI, which likely reflects changes in synaptic efficacy similar to LTP (Ziemann et al., 1998). Therefore, the combination of rTMS and INB allowed us to explore the effects of CNS-active drugs on plastic phenomena that are more pronounced and likely involve a larger number of distinct mechanisms when compared with the plastic changes induced by INB alone.

Sessions 1 and 6 were control sessions (Con1 and Con2, respectively), which meant that there was no further intervention. In sessions $2-5$, subjects were treated either with a single oral dose of $150 \mathrm{mg}$ of dextromethorphan (DM), $2 \mathrm{mg}$ of lorazepam (LZP), or $300 \mathrm{mg}$ of lamotrigine (LTG) or with sleep deprivation (SLD). The drugs were taken 2.5-3 hr before the start of an experimental session. Previous TMS experiments (Ziemann et al., 1996a,b) showed that this delay falls into a period in which all of these drugs exhibit significant suppressive effects on motor excitability. SLD was maintained for one full night preceding the experimental session. Each subject was assigned to the four interventions in sessions $2-5$ in a pseudorandomized order. The drugs were administered in a double-blind design. One of two figure eight-shaped stimulating coils, which differed in maximum magnetic field strength (difference, $\sim 30 \%$ ) but were otherwise identical, was used. Although the coil was the same in one session, the coil was changed between sessions. This introduced some variability across the preischemic measurements so that the known drug effects on motor excitability (Ziemann et al., 1996a,b) could remain hidden to the experimenter, who was unaware of which magnetic coil was used. This was an additional reassurance of the blind status of the investigator toward the intervention. Sessions $2-5$ were separated by 1 week each to avoid potential drug interactions between sessions. Each subject was tested at approximately the same time of day in each of the sessions. Side effects of the drugs were generally mild (sedation, ataxia, and nausea) and did not interfere with the ability of the subjects to comply fully with the requirements of the experimental protocol.

The three drugs were selected for their main modes of action. DM is a potent noncompetitive NMDA receptor antagonist (Wong et al., 1988) and in addition blocks voltage-gated $\mathrm{Ca}^{2+}$ and $\mathrm{Na}^{+}$channels at higher concentrations (Netzer et al., 1993). LZP [7-chloro-5-(o-chlorophenyl)1,3-dihydro-3-hydroxy-2H-1,4-benzodiazepin-2-one] is a short-acting benzodiazepine that enhances $\mathrm{Cl}^{-}$currents via the $\mathrm{GABA}_{\mathrm{A}}$ receptor (Macdonald, 1995). LTG [3,5-diamino-6-(2,3-dichlorophenyl)-1,2,4triazine] is a new antiepileptic drug that principally blocks voltage-gated $\mathrm{Na}^{+}$and $\mathrm{Ca}^{2+}$ channels (Leach et al., 1995; Stefani et al., 1996; Wang et al., 1996) but also reduces glutamate release (Leach et al., 1986).

Statistical analysis. Each measure of motor excitability (MT, MEP size, and ICI) was analyzed separately. Excitability late into ischemia and 20 and $60 \mathrm{~min}$ after ischemia was expressed as a difference from the preischemic value. The two differences in MEP size coming from the two stimulus intensities (130 and $150 \%$ of MT) and the two differences for ICI coming from the two ISIs ( 2 and $4 \mathrm{msec}$ ) were averaged, so that for each excitability measure only one value per time point and subject entered the analysis. A two-way factorial ANOVA was used to assess the main effects of intervention and time. Conditional on significant $\mathrm{F}$ values, post hoc pairwise comparisons between all interventions were performed with Fisher's protected least significant difference multiple $t$ statistic. Results were considered significant at the level of $p<0.05$.

\section{RESULTS}

Intervention had no effect on INB plus rTMS-induced changes in MT $\left[F_{\text {intervention(5,90) }}=0.19\right]$, but time was an effective factor $\left[F_{\text {time }(2,90)}=10.21 ; p=0.0001\right]$ (Fig. 1). Irrespective of intervention, INB plus rTMS induced a small, nonsignificant increase in MT late into ischemia (post hoc multiple $t$ statistic, $p>0.05$ ), 
Motor threshold

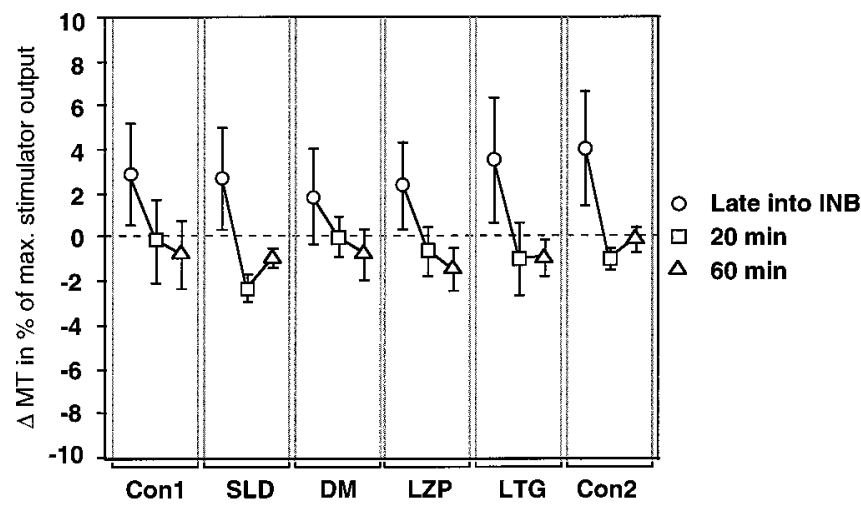

Figure 1. Effect of intervention on the changes in MT induced by ischemic forearm deafferentation and repetitive transcranial magnetic stimulation of the motor cortex contralateral to the side of ischemic nerve block. Changes in MT measured late into ischemia (circles) and $20 \mathrm{~min}$ (squares) and 60 min (triangles) after the end of ischemia are shown as differences from measurements obtained before the start of ischemia. These differences are given as a percentage of the maximal stimulator output ( $y$-axis). Data are mean values of six subjects; error bars indicate SEM. Interventions are indicated ( $x$-axis).

which returned to or was even less than the preischemic MT when measured 20 and $60 \mathrm{~min}$ after ischemia (Fig. 1). The interaction between intervention and time was not significant $\left[F_{(10,90)}=0.18\right]$.

Intervention had a significant effect on the INB plus rTMSinduced changes in MEP size $\left[F_{\text {intervention(5,90) }}=2.56 ; p=0.033\right]$. The effect of time was also significant $\left[F_{\text {time }(2,90)}=12.06 ; p<\right.$ $0.0001]$, whereas the interaction between intervention and time was not significant $\left[F_{(10,90)}=0.27\right]$ (Fig. 2). A post hoc analysis revealed that the MEP changes under the influence of LZP were different from the changes in the Con1 $(p=0.046)$, Con2 $(p=$ $0.0042)$, and SLD ( $p=0.023)$ conditions. Furthermore, the MEP changes under LTG were different from those in the Con2 ( $p=$ 0.012 ) condition. Figure 2 shows that these differences were clearly the result of suppression of the INB plus rTMS-induced increase in MEP size by LZP and LTG.

The INB plus rTMS-induced changes in ICI were also significantly affected by intervention $\left[F_{\text {intervention(5,90) }}=2.60 ; p=\right.$ $0.031]$, whereas the effects of time $\left[F_{\text {time }(2,90)}=0.37\right]$ and the interaction between intervention and time $\left[F_{(10,90)}=0.56\right]$ were not significant (Fig. 3). A post hoc analysis demonstrated that the INB plus rTMS-induced changes in ICI under the influence of LZP were significantly different from those in the Con1 ( $p=$ $0.014)$, Con2 ( $p=0.048)$, and SLD $(p=0.017)$ conditions. Changes in ICI under LTG were different from those in the Con1 $(p=0.049)$ condition, and changes in ICI under DM were different from those in the Con1 $(p=0.032)$ and SLD $(p=$ 0.038 ) conditions. Figure 3 shows that these differences were the result of suppression of the INB plus rTMS-induced disinhibition by these drugs.

Figure 4 illustrates the effects of intervention on the INB plus rTMS-induced changes in MEP size and in ICI in a single subject. The EMG recordings show that the INB plus rTMSinduced increase in MEP size (Fig. 4A) was completely suppressed by LTG and by LZP but not by DM. The INB plus rTMS-induced reduction in ICI (Fig. 4B) was abolished by LTG and clearly suppressed by LZP and by DM.

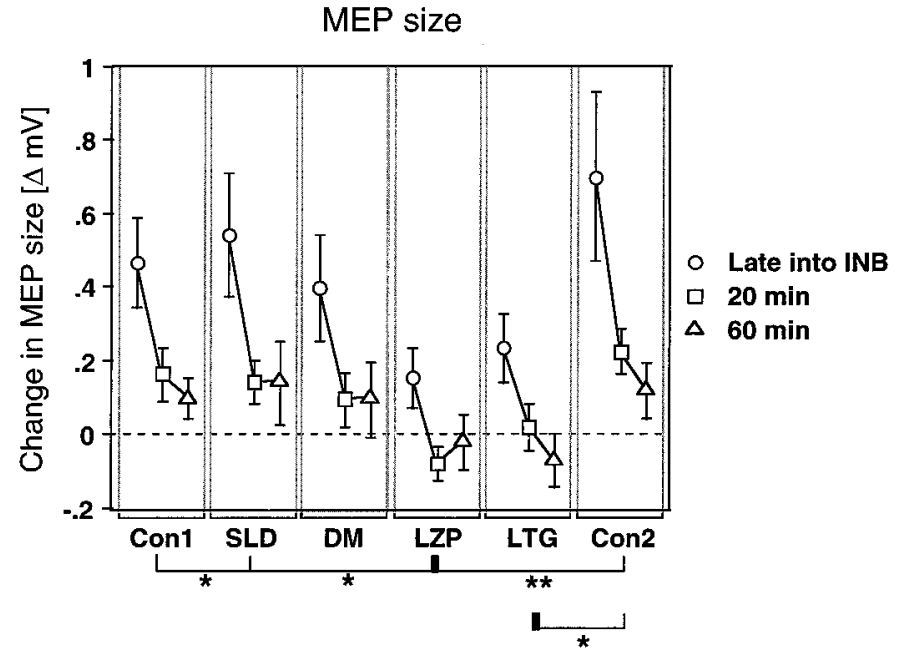

Figure 2. Effect of intervention on the increase in MEP amplitude induced by ischemic forearm deafferentation and repetitive transcranial magnetic stimulation of the motor cortex contralateral to the side of ischemic nerve block. Changes in MEP size measured late into ischemia (circles) and $20 \mathrm{~min}$ (squares) and $60 \mathrm{~min}$ (triangles) after the end of ischemia are given as differences $(\Delta \mathrm{mV})$ from the values obtained before ischemic nerve block, which were assigned a value of 0 ( $y$-axis). Other conventions and arrangements are described in Figure 1. Note that LZP and LTG led to suppression of the ischemia plus transcranial magnetic stimulation-induced increase in MEP size. ${ }^{*} p<0.05$; ${ }^{*} p<0.01$.

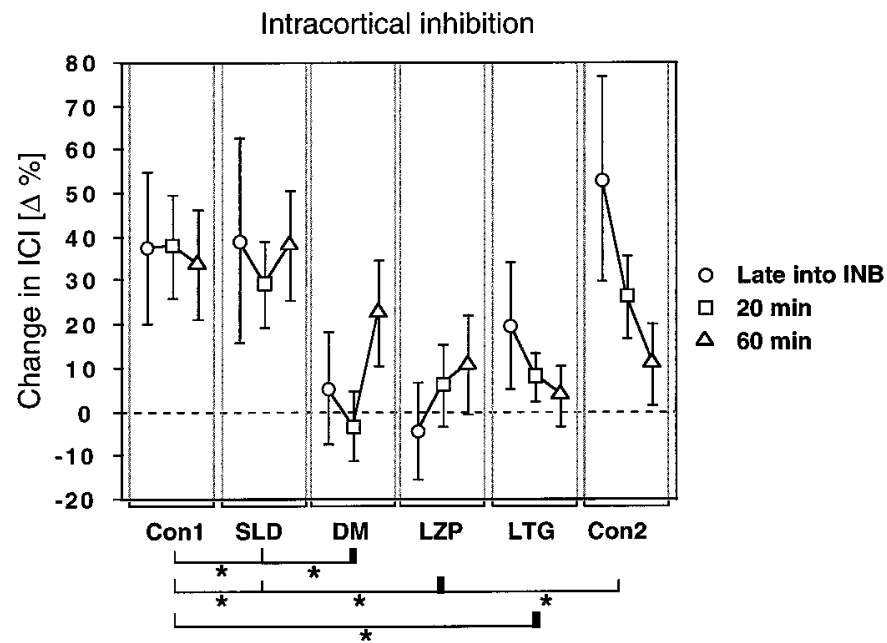

Figure 3. Effect of intervention on the decrease in ICI induced by ischemic forearm deafferentation and repetitive transcranial magnetic stimulation of the motor cortex contralateral to the side of ischemic nerve block. ICI values measured late into ischemia (circles) and $20 \mathrm{~min}$ (squares) and $60 \mathrm{~min}$ (triangles) after the end of ischemia are given as differences from the values obtained before ischemic nerve block. Because ICI values are percentages of conditioned to control motor-evoked potential amplitudes, the changes in ICI are expressed in $\Delta \%$ ( $y$-axis). Differences $>0$ indicate a decrease in ICI. Other conventions and arrangements are described in Figures 1 and 2. Note that DM, LZP, and LTG led to significant suppression of the ischemia plus transcranial magnetic stimulation-induced decrease in intracortical inhibition. ${ }^{*} p<$ 0.05 .

\section{DISCUSSION}

Temporary ischemic forearm deafferentation combined with lowfrequency rTMS of the motor cortex contralateral to the side of ischemia leads to a rapid increase in the excitability of the motor 
A

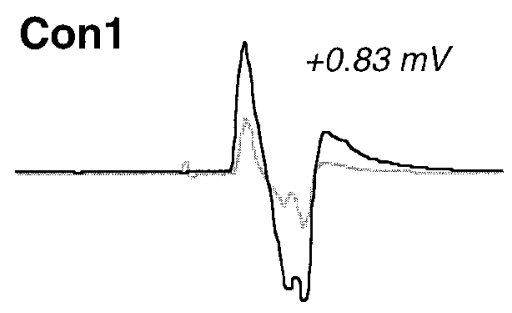

LTG

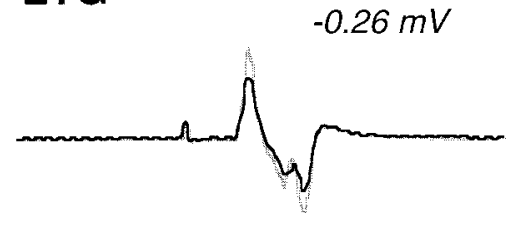

B
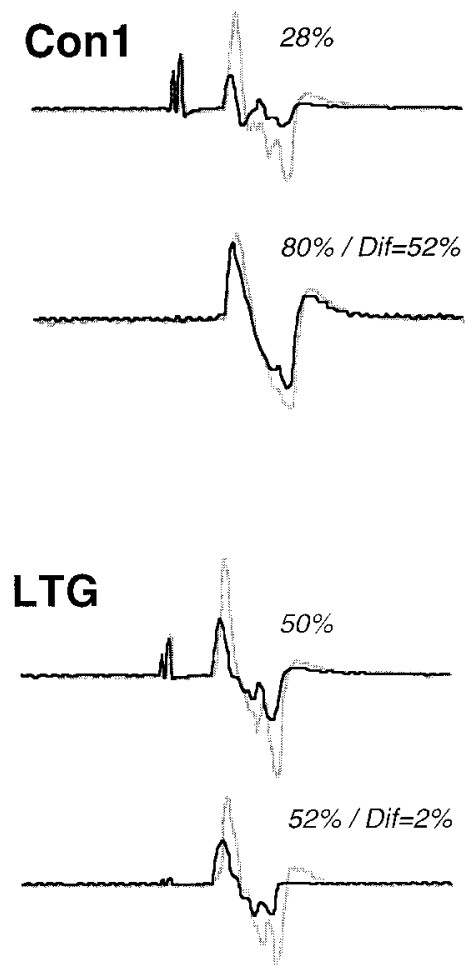
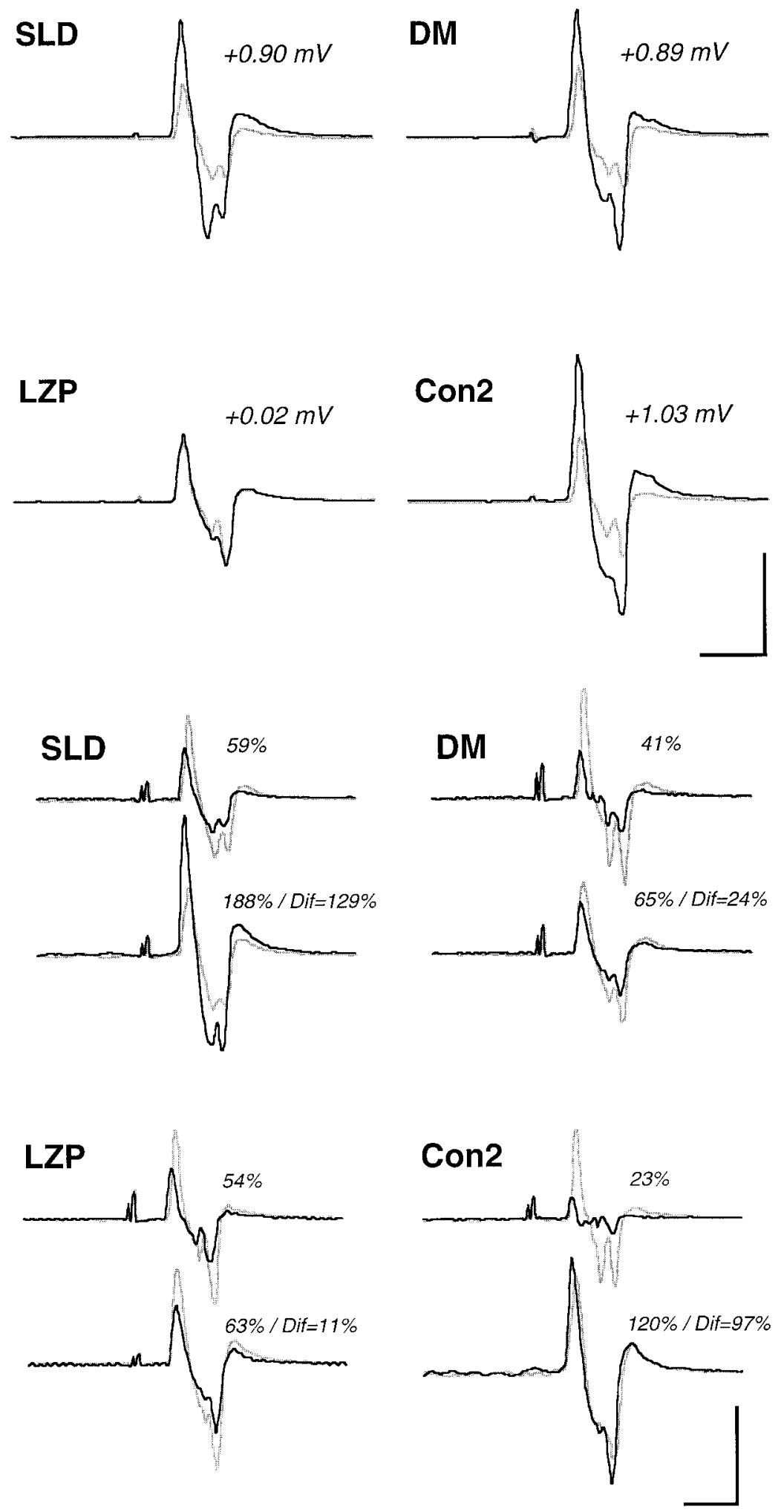

Figure 4. EMG recordings from the biceps brachii muscle of one subject, illustrating the effects of intervention on the increase in MEP size $(A)$ and on the decrease in intracortical inhibition $(B)$ induced by ischemic forearm deafferentation and repetitive transcranial magnetic stimulation of the motor cortex contralateral to ischemic nerve block. A, MEPs obtained before ischemic nerve block (gray lines) and late into ischemia (black lines) are superimposed. The numbers (in $\mathrm{mV}$ ) refer to the deafferentation-induced change in MEP size. $B$, Control MEPs produced by the test stimulus alone (gray lines) and MEPs elicited by paired stimulation at an interstimulus interval of $2 \mathrm{msec}$ (black lines) are superimposed. For each intervention, the top and bottom traces refer to MEPs obtained before and late into forearm ischemia, respectively. The percentages indicate the amount of intracortical inhibition and the difference (Dif) in intracortical inhibition before and late into ischemia. All MEPs are averages of eight single trials. Calibration bars: $A, 20 \mathrm{msec}, 0.5 \mathrm{mV} ; B, 20 \mathrm{msec}, 0.25 \mathrm{mV}$. Note that LTG and LZP led to virtually complete abolition of the deafferentation-induced increase in MEP size in this subject. Furthermore, both of these drugs and DM had a suppressive effect on the deafferentation-induced decrease in intracortical inhibition. 


\begin{tabular}{|c|c|c|c|c|c|c|c|c|}
\hline & Con1 & SLD & DM & LZP & LTG & Con 2 & $F$ & $p$ \\
\hline $\mathrm{CMB}$ & $28.5 \pm 5.3$ & $30.6 \pm 6.3$ & $30.2 \pm 5.0$ & $29.3 \pm 4.4$ & $30.2 \pm 4.4$ & $31.4 \pm 7.3$ & 0.21 & NS \\
\hline $\mathrm{TI}$ & $45.5 \pm 6.1$ & $46.1 \pm 6.7$ & $46.4 \pm 5.2$ & $45.4 \pm 4.5$ & $46.2 \pm 4.3$ & $46.5 \pm 7.6$ & 0.04 & NS \\
\hline
\end{tabular}

Values are means \pm SD (in minutes) from six subjects. CMB, Time to complete motor block; TI, total time of ischemia.

\begin{tabular}{|c|c|c|c|c|c|c|c|c|}
\hline & Con1 & SLD & DM & LZP & LTG & Con 2 & $F$ & $p$ \\
\hline MT(BB) & $51.2 \pm 7.1$ & $53.5 \pm 8.4$ & $51.8 \pm 7.9$ & $52.7 \pm 4.4$ & $52.5 \pm 6.2$ & $51.0 \pm 8.1$ & 0.11 & NS \\
\hline MT(APB) & $49.8 \pm 6.9$ & $49.0 \pm 7.7$ & $51.3 \pm 8.8$ & $52.0 \pm 3.6$ & $49.8 \pm 2.9$ & $49.7 \pm 6.9$ & 0.28 & NS \\
\hline MEP & $0.50 \pm 0.30$ & $0.50 \pm 0.52$ & $0.68 \pm 0.52$ & $0.57 \pm 0.38$ & $0.52 \pm 0.41$ & $0.51 \pm 0.38$ & 0.32 & NS \\
\hline ICI & $41 \pm 23$ & $53 \pm 19$ & $49 \pm 31$ & $64 \pm 31$ & $49 \pm 28$ & $51 \pm 32$ & 1.11 & NS \\
\hline
\end{tabular}

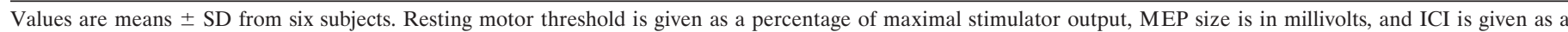
percentage of control MEP size. MT(BB), Motor threshold for biceps brachii muscle; MT(APB), motor threshold for abductor pollicis brevis muscle.

cortical representation targeting the $\mathrm{BB}$ proximal to the ischemic level. The present study shows that a single oral dose of the benzodiazepine LZP, the NMDA receptor antagonist DM, or the voltage-gated $\mathrm{Na}^{+}$and $\mathrm{Ca}^{2+}$ channel blocker LTG affects this form of plasticity to different extents.

Nonspecific factors for these findings were eliminated by the fact that the time to complete motor block, the total time of ischemia (Table 1), and the preischemic values for MT, MEP size, and ICI (Table 2) were not different between interventions. Comparison of motor excitability across experimental sessions several days apart and the random use of two different stimulation coils introduced a slightly larger variability in testing than was reported previously (Ziemann et al., 1996a,b). Because preischemic MEP size was slightly, although not significantly, larger and ICI was less prominent in the drug sessions compared with at least one of the control sessions (Table 2), a "floor effect" cannot explain the suppressive drug effects on INB plus rTMS-induced changes in MEP size and in ICI.

The INB-induced increase in MEP size in muscles proximal to the ischemic nerve block (Brasil-Neto et al., 1992, 1993; Ridding and Rothwell, 1995, 1997; Ziemann et al., 1998) occurs at the level of the motor cortex, because subcortical and spinal excitability, tested with transcranial electrical stimulation, spinal electrical stimulation, and Hoffmann reflexes, did not change (Brasil-Neto et al., 1993). The increase in MEP size then reflects enhanced excitability of corticocortical excitatory connections, given that TMS activates corticospinal neurons predominately indirectly (Day et al., 1989; Nakamura et al., 1997). The INB plus rTMSinduced decrease in ICI reflects mainly a reduction in GABArelated motor cortical inhibition (Kujirai et al., 1993; Ziemann et al., 1996c). However, recent evidence showed that ICI consists of weak excitatory in addition to strong inhibitory effects (Ridding et al., 1995; Ziemann et al., 1996b); thus an enhancement of excitatory mechanisms may also contribute to the decrease in ICI. For two reasons, it was proposed that the rTMS-induced reduction in ICI is associated with an LTP-like phenomenon; (1) this reduction lasted for at least $60 \mathrm{~min}$ after the end of ischemic deafferentation, and (2) it was dependent on the INB-induced hyperexcitability of the plastic cortex, because in the absence of ischemia, rTMS did not cause any change in ICI (Ziemann et al., 1998). This is reminiscent of the need for sufficient depolarization of the postsynaptic site to allow the occurrence of LTP in the neocortex (Artola and Singer, 1987; Artola et al., 1990; Kirkwood et al.,
1993; Hess and Donoghue, 1994; Kirkwood and Bear, 1994; Hess et al., 1996). Depolarization of the postsynaptic site can be achieved by local application of bicuculline, a $\mathrm{GABA}_{\mathrm{A}}$ receptor antagonist, before afferent tetanic stimulation is started to induce LTP. The downregulation of GABAergic cortical circuits was proposed to be of crucial importance in deafferentation-induced plasticity (Jones, 1993). This idea is supported by various animal models of deafferentation, which showed a decrease in glutamic acid decarboxylase, the GABA synthetic enzyme (Hendry and Jones, 1986, 1988; Welker et al., 1989; Akhtar and Land, 1991), in GABA (Hendry and Jones, 1986, 1988; Garraghty et al., 1991; Rosier et al., 1995), and in GABA receptors (Hendry et al., 1990). However, it is unclear how soon changes in GABA can occur after the onset of deafferentation. None of these studies started to investigate GABA earlier than 3-5 d after the lesion, at which time the downregulation of GABA was fully expressed (Hendry and Jones, 1988; Welker et al., 1989).

The suppression of the INB plus rTMS-induced increase in MEP size and the decrease in ICI by the $\mathrm{GABA}_{\mathrm{A}}$ receptor agonist LZP in the present experiments suggest that the rapid removal of GABA-related inhibition is a permissive and necessary step for this form of deafferentation-induced plasticity to occur in the human motor cortex. An intriguing example of the importance of GABA-related circuitry in the mediation of rapid cortical plasticity was the appearance of a "new" forelimb representation in the vibrissae motor cortex of adult rats after GABA receptors in the adjacent forelimb motor cortex were blocked (Jacobs and Donoghue, 1991). These changes were probably caused by unmasking of normally latent excitatory connections from vibrissae to forelimb motor cortex. Other animal studies explored the effect of modulation of GABA-related inhibition on LTP induction in the hippocampus and showed that it was blocked by LZP (Riches and Brown, 1986) and other benzodiazepines (Satoh et al., 1986; del Cerro et al., 1992; Evans and Viola-McCabe, 1996) but facilitated by GABA receptor blockers (Wigström and Gustafsson, 1983).

The main mode of action of DM is a noncompetitive blockade of NMDA receptors (Wong et al., 1988; Netzer et al., 1993). In the present study, DM produced suppression of the INB plus rTMS-induced changes in ICI but had no significant effect on the increase in MEP size, which suggests that the INB plus rTMSinduced reduction in ICI but not the increase in MEP size was dependent on NMDA receptor-mediated plasticity. This further 
suggests that the decrease in ICI is interrelated with an LTP-like phenomenon, because LTP requires the activation of NMDA receptors (Collingridge et al., 1983; Artola and Singer, 1987; Kirkwood et al., 1993; Kirkwood and Bear, 1994; Hess et al., 1996). The present findings are also compatible with evidence from animal experiments that deafferentation-induced neocortical plasticity can be disrupted by NMDA receptor blockers (Kleinschmidt et al., 1987; Bear et al., 1990; Kano et al., 1991; Garraghty and Muja, 1996).

LTG blocks voltage-gated $\mathrm{Na}^{+}$channels (Leach et al., 1995) and also high voltage-gated $\mathrm{Ca}^{2+}$ currents (Stefani et al., 1996; Wang et al., 1996) and glutamate release (Leach et al., 1986). In the present experiments, LTG had a suppressive effect on the INB plus rTMS-induced changes in both MEP size and ICI. It is likely that the blockade of $\mathrm{Na}^{+}$and $\mathrm{Ca}^{2+}$ channels and/or the reduced glutamate release led to a decrease in the deafferentation-induced amount of depolarization in motor cortex output cells. Insufficient depolarization may then have prevented changes in MEP size and ICI from occurring. If a PTPlike mechanism had contributed to the INB plus rTMS-induced short-lasting changes in MEP size, this could explain why LTG but not DM had a suppressive effect, because PTP depends on the accumulation of $\mathrm{Ca}^{2+}$ and probably also $\mathrm{Na}^{+}$in presynaptic terminals (Fisher et al., 1997) but not on NMDA receptor activation (Malenka, 1991). Although no experimental data are available about the effects of LTG on PTP, drugs with a very similar main mode of action, such as phenytoin, are potent blockers of PTP (Selzer et al., 1985; Griffith and Taylor, 1988). In addition, the changes in ICI may also have been suppressed by the blockade of $\mathrm{Ca}^{2+}$ channels, because a LTP component has been described that is independent of NMDA receptor activation but is dependent on voltage-gated $\mathrm{Ca}^{2+}$ channels (Grover and Teyler, 1990). Accordingly, LTG blocked this component of LTP in animal experiments (Wang et al., 1997).

In conclusion, the effects of CNS-active drugs in the present model of INB plus rTMS-induced plasticity in human sensorimotor cortex provide evidence that the deafferentation-induced increase in MEP size involved rapid downregulation of GABArelated inhibitory circuits and a mechanism mediated via voltagegated $\mathrm{Na}^{+}$or $\mathrm{Ca}^{2+}$ channels, either depolarization of motor cortical output cells or a PTP-like mechanism at presynaptic terminals. The rTMS-induced reduction in ICI was long lasting (>60 min), involved NMDA receptor activation, and therefore was likely interrelated with a LTP-like mechanism. The present study introduces a noninvasive experimental model for evaluating mechanisms of plasticity, in this case deafferentation-induced, in intact adult humans. Identification of the specific mechanisms involved in plastic changes in the human cerebral cortex is the necessary first step toward a definition of rationally founded therapeutic strategies in the reorganization of human cortex, that is, the promotion of functionally beneficial (Cohen et al., 1997) but the suppression of probably maladaptive plasticity (Ramachandran et al., 1992; Yang et al., 1994; Flor et al., 1995; Knecht et al., 1995).

\section{REFERENCES}

Akhtar ND, Land PW (1991) Activity-dependent regulation of glutamic acid decarboxylase in the rat barrel cortex: effects of neonatal versus adult sensory deprivation. J Comp Neurol 307:200-213.

Artola A, Singer W (1987) Long-term potentiation and NMDA receptors in rat visual cortex. Nature 330:649-652.

Artola A, Brocher S, Singer W (1990) Different voltage-dependent thresholds for inducing long-term depression and long-term potentiation in slices of rat visual cortex. Nature 347:69-72.

Bear MF, Kleinschmidt A, Gu QA, Singer W (1990) Disruption of experience-dependent synaptic modifications in striate cortex by infusion of an NMDA receptor antagonist. J Neurosci 10:909-925.

Bliss TV, Lømo T (1973) Long-lasting potentiation of synaptic transmission in the dentate area of the anaesthetized rabbit following stimulation of the perforant path. J Physiol (Lond) 232:331-356.

Borsook D, Becerra L, Fishman S, Edwards A, Jennings CL, Stojanovic M, Papinicolas L, Ramachandran VS, Gonzalez RG, Breiter H (1998) Acute plasticity in the human somatosensory cortex following amputation. NeuroReport 9:1013-1017.

Brasil-Neto JP, Cohen LG, Pascual-Leone A, Jabir FK, Wall RT, Hallett M (1992) Rapid reversible modulation of human motor outputs after transient deafferentation of the forearm: a study with transcranial magnetic stimulation. Neurology 42:1302-1306.

Brasil-Neto JP, Valls-Sole J, Pascual-Leone A, Cammarota A, Amassian VE, Cracco R, Maccabee P, Cracco J, Hallett M, Cohen LG (1993) Rapid modulation of human cortical motor outputs following ischaemic nerve block. Brain 116:511-525.

Brouwer B, Ashby P (1990) Corticospinal projections to upper and lower limb spinal motoneurons in man. Electroencephalogr Clin Neurophysiol 76:509-519.

Byrne JA, Calford MB (1991) Short-term expansion of receptive fields in rat primary somatosensory cortex after hindpaw digit denervation. Brain Res 565:218-224.

Calford MB, Tweedale R (1988) Immediate and chronic changes in responses of somatosensory cortex in adult flying-fox after digit amputation. Nature 332:446-448.

Calford MB, Tweedale R (1991a) Acute changes in cutaneous receptive fields in primary somatosensory cortex after digit denervation in adult flying fox. J Neurophysiol 65:178-187.

Calford MB, Tweedale R (1991b) Immediate expansion of receptive fields of neurons in area $3 \mathrm{~b}$ of macaque monkeys after digit denervation. Somatosens Mot Res 8:249-260.

Castro-Alamancos MA, Donoghue JP, Connors BW (1995) Different forms of synaptic plasticity in somatosensory and motor areas of the neocortex. J Neurosci 15:5324-5333.

Chen R, Classen J, Gerloff C, Celnik P, Wassermann EM, Hallett M, Cohen LG (1997a) Depression of motor cortex excitability by lowfrequency transcranial magnetic stimulation. Neurology 48:1398-1403.

Chen R, Samii A, Canos M, Wassermann EM, Hallett M (1997b) Effects of phenytoin on cortical excitability in humans. Neurology 49:881-883.

Cohen LG, Celnik P, Pascual-Leone A, Corwell B, Faiz L, Dambrosia J, Honda M, Sadato N, Gerloff C, Catala MD, Hallett M (1997) Functional relevance of cross-modal plasticity in the blind. Nature 389:180-183.

Collingridge GL, Kehl SJ, McLennan H (1983) Excitatory amino acids in synaptic transmission in the Schaffer collateral-commissural pathway of the rat hippocampus. J Physiol (Lond) 334:33-46.

Day BL, Dressler D, Maertens de Noordhout A, Marsden CD, Nakashima K, Rothwell JC, Thompson PD (1989) Electric and magnetic stimulation of the human motor cortex: surface EMG and single motor unit responses. J Physiol (Lond) 412:449-473.

del Cerro S, Jung M, Lynch G (1992) Benzodiazepines block long-term potentiation in slices of hippocampus and piriform cortex. Neuroscience 49:1-6.

Di Lazzaro V, Restuccia D, Oliviero A, Profice P, Ferrara L, Insola A, Mazzone P, Tonali P, Rothwell JC (1998) Magnetic transcranial stimulation at intensities below active motor threshold activates intracortical inhibitory circuits. Exp Brain Res 119:265-268.

Donoghue JP, Suner S, Sanes JN (1990) Dynamic organization of primary motor cortex output to target muscles in adult rats. II. Rapid reorganization following motor nerve lesions. Exp Brain Res 79:492-503.

Donoghue JP, Hess G, Sanes JN (1996) Substrates and mechanisms for learning in motor cortex. In: Acquisition of motor behavior in vertebrates (Bloedel J, Ebner T, Wise SP, eds), pp 363-386. Cambridge, MA: MIT.

Evans MS, Viola-McCabe KE (1996) Midazolam inhibits long-term potentiation through modulation of GABAA receptors. Neuropharmacology 35:347-357.

Fisher SA, Fischer TM, Carew TJ (1997) Multiple overlapping processes underlying short-term synaptic enhancement. Trends Neurosci 20:170-177. 
Flor H, Elbert T, Knecht S, Wienbruch C, Pantev C, Birbaumer N, Larbig W, Taub E (1995) Phantom-limb pain as a perceptual correlate of cortical reorganization following arm amputation. Nature 375:482-484.

Garraghty PE, Muja N (1996) NMDA receptors and plasticity in adult primate somatosensory cortex. J Comp Neurol 367:319-326.

Garraghty PE, LaChica EA, Kaas JH (1991) Injury-induced reorganization of somatosensory cortex is accompanied by reductions in GABA staining. Somatosens Mot Res 8:347-354.

Grafton ST, Mazziotta JC, Presty S, Friston KJ, Frackowiak RS, Phelps ME (1992) Functional anatomy of human procedural learning determined with regional cerebral blood flow and PET. J Neurosci 12:2542-2548.

Griffith WH, Taylor L (1988) Phenytoin reduces excitatory synaptic transmission and post-tetanic potentiation in the in vitro hippocampus. J Pharmacol Exp Ther 246:851-858.

Grover LM, Teyler TJ (1990) Two components of long-term potentiation induced by different patterns of afferent activation. Nature 347:477-479.

Hendry SH, Jones EG (1986) Reduction in number of immunostained GABAergic neurones in deprived-eye dominance columns of monkey area 17. Nature 320:750-753.

Hendry SH, Jones EG (1988) Activity-dependent regulation of GABA expression in the visual cortex of adult monkeys. Neuron 1:701-712.

Hendry SH, Fuchs J, deBlas AL, Jones EG (1990) Distribution and plasticity of immunocytochemically localized GABAA receptors in adult monkey visual cortex. J Neurosci 10:2438-2450.

Hess G, Donoghue JP (1994) Long-term potentiation of horizontal connections provides a mechanism to reorganize cortical motor maps. J Neurophysiol 71:2543-2547.

Hess G, Aizenman CD, Donoghue JP (1996) Conditions for the induction of long-term potentiation in layer II/III horizontal connections of the rat motor cortex. J Neurophysiol 75:1765-1778.

Huntley GW (1997) Correlation between patterns of horizontal connectivity and the extent of short-term representational plasticity in rat motor cortex. Cereb Cortex 7:143-156.

Iriki A, Pavlides C, Keller A, Asanuma H (1989) Long-term potentiation in the motor cortex. Science 245:1385-1387.

Jacobs KM, Donoghue JP (1991) Reshaping the cortical motor map by unmasking latent intracortical connections. Science 251:944-947.

Jones EG (1993) GABAergic neurons and their role in cortical plasticity in primates. Cereb Cortex 3:361-372.

Kaneko K, Kawai S, Fuchigami Y, Morita H, Ofuji A (1996) The effect of current direction induced by transcranial magnetic stimulation on the corticospinal excitability in human brain. Electroencephalogr Clin Neurophysiol 101:478-482.

Kano M, Iino K, Kano M (1991) Functional reorganization of adult cat somatosensory cortex is dependent on NMDA receptors. NeuroReport 2:77-80.

Karni A, Meyer G, Jezzard P, Adams MM, Turner R, Ungerleider LG (1995) Functional MRI evidence for adult motor cortex plasticity during motor skill learning. Nature 377:155-158.

Kirkwood A, Bear MF (1994) Hebbian synapses in visual cortex. J Neurosci 14:1634-1645.

Kirkwood A, Dudek SD, Gold JT, Aizenman CD, Bear MF (1993) Common forms of synaptic plasticity in hippocampus and neocortex. Science 260:1518-1521.

Kleinschmidt A, Bear MF, Singer W (1987) Blockade of "NMDA" receptors disrupts experience-dependent plasticity of kitten striate cortex. Science 238:355-358.

Knecht S, Henningsen H, Elbert T, Flor H, Hohling C, Pantev C, Birbaumer N, Taub E (1995) Cortical reorganization in human amputees and mislocalization of painful stimuli to the phantom limb. Neurosci Lett 201:262-264.

Kolarik RC, Rasey SK, Wall JT (1994) The consistency, extent, and locations of early-onset changes in cortical nerve dominance aggregates following injury of nerves to primate hands. J Neurosci 14:4269-4288.

Kujirai T, Caramia MD, Rothwell JC, Day BL, Thompson PD, Ferbert A, Wroe S, Asselman P, Marsden CD (1993) Corticocortical inhibition in human motor cortex. J Physiol (Lond) 471:501-519.

Leach MJ, Marden CM, Miller AA (1986) Pharmacological studies on lamotrigine, a novel potential antiepileptic drug: II. Neurochemical studies on the mechanism of action. Epilepsia 27:490-497.

Leach MJ, Lees G, Riddall DR (1995) Lamotrigine. Mechanisms of action. In: Antiepileptic drugs (Levy RH, Mattson RH, Meldrum BS, eds), pp 861-869. New York: Raven.
Liepert J, Schwenkreis P, Tegenthoff M, Malin J-P (1997) The glutamate antagonist Riluzole suppresses intracortical facilitation. J Neural Transm 104:1207-1214.

Macdonald RL (1995) Benzodiazepines. Mechanisms of action. In: Antiepileptic drugs (Levy RH, Mattson RH, Meldrum BS, eds), pp 695703. New York: Raven.

Malenka RC (1991) Postsynaptic factors control the duration of synaptic enhancement in area CA1 of the hippocampus. Neuron 6:53-60.

Mavroudakis N, Caroyer JM, Brunko E, Zegers de Beyl D (1994) Effects of diphenylhydantoin on motor potentials evoked with magnetic stimulation. Electroencephalogr Clin Neurophysiol 93:428-433.

Merzenich MM, Kaas JH, Wall JT, Sur M, Nelson RJ, Felleman DJ (1983) Progression of change following median nerve section in the cortical representation of the hand in areas $3 \mathrm{~b}$ and 1 in adult owl and squirrel monkeys. Neuroscience 10:639-665.

Nakamura H, Kitagawa H, Kawaguchi Y, Tsuji H (1997) Intracortical facilitation and inhibition after transcranial magnetic stimulation in conscious humans. J Physiol (Lond) 498:817-823.

Netzer R, Pflimlin P, Trube G (1993) Dextromethorphan blocks $N$-methyl-D-aspartate-induced currents and voltage-operated inward currents in cultured cortical neurons. Eur J Pharmacol 238:209-216.

Nudo RJ, Milliken GW, Jenkins WM, Merzenich MM (1996) Usedependent alterations of movement representations in primary motor cortex of adult squirrel monkeys. J Neurosci 16:785-807.

Pascual-Leone A, Grafman J, Hallett M (1994) Modulation of cortical motor output maps during development of implicit and explicit knowledge. Science 263:1287-1289.

Pascual-Leone A, Nguyet D, Cohen LG, Brasil-Neto JP, Cammarota A, Hallett M (1995) Modulation of muscle responses evoked by transcranial magnetic stimulation during the acquisition of new fine motor skills. J Neurophysiol 74:1037-1045.

Ramachandran VS, Stewart M, Rogers-Ramachandran DC (1992) Perceptual correlates of massive cortical reorganization. NeuroReport 3:583-586.

Recanzone GH, Merzenich MM, Jenkins WM, Grajski KA, Dinse HR (1992) Topographic reorganization of the hand representation in cortical area $3 \mathrm{~b}$ of owl monkeys trained in a frequency-discrimination task. J Neurophysiol 67:1031-1056.

Riches IP, Brown MW (1986) The effect of lorazepam upon hippocampal long-term potentiation. Neurosci Lett [Suppl] 24:S42.

Ridding MC, Rothwell JC (1995) Reorganisation in human motor cortex. Can J Physiol Pharmacol 73:218-222.

Ridding MC, Rothwell JC (1997) Stimulus/response curves as a method of measuring motor cortical excitability in man. Electroencephalogr Clin Neurophysiol 105:340-344.

Ridding MC, Inzelberg R, Rothwell JC (1995) Changes in excitability of motor cortical circuitry in patients with Parkinson's disease. Ann Neurol 37:181-188.

Rosier AM, Arckens L, Demeulemeester H, Orban GA, Eysel UT, Wu YJ, Vandesande F (1995) Effect of sensory deafferentation on immunoreactivity of GABAergic cells and on GABA receptors in the adult cat visual cortex. J Comp Neurol 359:476-489.

Sanes JN, Donoghue JP (1997) Static and dynamic organization of motor cortex. Adv Neurol 73:277-296.

Sanes JN, Suner S, Lando JF, Donoghue JP (1988) Rapid reorganization of adult rat motor cortex somatic representation patterns after motor nerve injury. Proc Natl Acad Sci USA 85:2003-2007.

Satoh M, Ishihara K, Iwama T, Takagi H (1986) Aniracetam augments, and midazolam inhibits, the long-term potentiation in guinea-pig hippocampal slices. Neurosci Lett 68:216-220.

Schieber MH, Hibbard LS (1993) How somatotopic is the motor cortex hand area? Science 261:489-492.

Selzer ME, David G, Yaari Y (1985) On the mechanisms by which phenytoin blocks post-tetanic potentiation at the frog neuromuscular junction. J Neurosci 5:2894-2899.

Silva AC, Rasey SK, Wu X, Wall JT (1996) Initial cortical reactions to injury of the median and radial nerves to the hands of adult primates. J Comp Neurol 366:700-716.

Stefani A, Spadoni F, Siniscalchi A, Bernardi G (1996) Lamotrigine inhibits $\mathrm{Ca} 2+$ currents in cortical neurons: functional implications. Eur J Pharmacol 307:113-116. 
Wang SJ, Huang CC, Hsu KS, Tsai JJ, Gean PW (1996) Inhibition of $\mathrm{N}$-type calcium currents by lamotrigine in rat amygdalar neurones. NeuroReport 7:3037-3040.

Wang SJ, Tsai JJ, Gean PW (1997) Lamotrigine inhibits tetraethylammonium-induced synaptic plasticity in the rat amygdala. Neuroscience 81:667-671.

Welker E, Soriano E, Van der Loos H (1989) Plasticity in the barrel cortex of the adult mouse: effects of peripheral deprivation on GADimmunoreactivity. Exp Brain Res 74:441-452.

Wigström H, Gustafsson B (1983) Facilitated induction of hippocampal long-lasting potentiation during blockade of inhibition. Nature 301:603-604.

Wong BY, Coulter DA, Choi DW, Prince DA (1988) Dextrorphan and dextromethorphan, common antitussives, are antiepileptic and antagonize $N$-methyl-D-aspartate in brain slices. Neurosci Lett 85:261-266.
Yang TT, Gallen CC, Ramachandran VS, Cobb S, Schwartz BJ, Bloom FE (1994) Noninvasive detection of cerebral plasticity in adult human somatosensory cortex. NeuroReport 5:701-704.

Ziemann U, Lönnecker S, Steinhoff BJ, Paulus W (1996a) The effect of lorazepam on the motor cortical excitability in man. Exp Brain Res 109:127-135.

Ziemann U, Lönnecker S, Steinhoff BJ, Paulus W (1996b) Effects of antiepileptic drugs on motor cortex excitability in humans: a transcranial magnetic stimulation study. Ann Neurol 40:367-378.

Ziemann U, Rothwell JC, Ridding MC (1996c) Interaction between intracortical inhibition and facilitation in human motor cortex. J Physiol (Lond) 496:873-881.

Ziemann U, Corwell B, Cohen LG (1998) Modulation of plasticity in human motor cortex after forearm ischemic nerve block. J Neurosci 18:1115-1123. 